\title{
A Feasibility Study on the Potential Use of Near Infrared Reflectance Spectroscopy to Analyze Meat in Live Animals: Discrimination of Muscles
}

\author{
J. J. Roberts, J. Ch. Motin, D. Swain, and D. Cozzolino \\ School of Health, Medical and Applied Sciences, Central Queensland Innovation and Research Precinct (CQIRP), Central Queensland \\ University (CQU), Bruce Highway, North Rockhampton, QLD 4701, Australia
}

Correspondence should be addressed to D. Cozzolino; d.cozzolino@cqu.edu.au

Received 1 April 2017; Revised 15 June 2017; Accepted 20 July 2017; Published 14 September 2017

Academic Editor: Davide Ferri

Copyright (c) 2017 J. J. Roberts et al. This is an open access article distributed under the Creative Commons Attribution License, which permits unrestricted use, distribution, and reproduction in any medium, provided the original work is properly cited.

\begin{abstract}
Near infrared (NIR) spectroscopy has been proposed as a potential method to analyze different properties in live animals and humans, as infrared light has the ability to penetrate living tissues. This study evaluated the potential use of NIR spectroscopy to identify and analyze beef muscles through the skin nondestructively. The results from this study demonstrated that the NIR region has the potential to noninvasively monitor some properties of meat associated with either fat or muscle characteristics and to differentiate either muscle or fat tissue analyzed through the skin. At present, there are no rapid and noninvasive tools to monitor and assess any characteristic or property in live beef animals. Although these results look promising, more experiments and research need to be carried out before recommending the beef industry using this technology in live animals.
\end{abstract}

\section{Introduction}

Research in animal feeding and nutrition often requires the evaluation of live animals, postmortem carcass assessment, or meat composition to assess the nutritional value of feeds on animal performance $[1,2]$. However, conventional analytical methods currently in use by the food and beef industries are usually destructive (e.g., postmortem evaluation), time consuming, and expensive and require of the use of different chemical and physical methods [3-5].

Near infrared (NIR) spectroscopy has been proposed as a potential method to analyze different properties in live animals and humans, as infrared light penetrates living tissues [4, 6-9]. This technique has been applied in the agricultural industries since the 1960s in routine measurements of agricultural commodities and has expanded rapidly due to its relatively low cost, speed of analysis, and the ability to assess various quality aspects simultaneously [10-12].

It has been reported that NIR spectroscopy can detect tissue oxygenation changes in the brain and muscle of humans where the detection of tissue oxygenation is possible because of the relative transparency of biological tissues to NIR wavelengths [9]. This type of application uses the oxygen-dependent absorption spectra of the main tissue chromophores-haemoglobin, myoglobin, and cytochrome $c$ oxidase at different wavelengths in the NIR region [9]. It has been also reported that pigmented tissues can reduce the NIR signal intensity and since animals have both extensive hair covering and heavily pigmented epidermal tissues, these might interfere with the NIR spectra of the tissue analyzed [13-15].

Short wavelengths (SW) in the NIR (700 to $1100 \mathrm{~nm}$; 13,900 to $9400 \mathrm{~cm}^{-1}$ ) range can penetrate deeply into the skin, offering a potential spectral window for the analysis of animal and human tissues $[2,4,16]$. In recent years, researchers in Spain have demonstrated the potential of NIR spectroscopy as a very easy and quick tool for the quantitative and qualitative analysis of quality parameters in meat and as a tool for carcass or product grading $[2,4,16]$. In addition, these authors have indicated that in vivo or on-the-skin NIR measurements at the farm or slaughterhouse have shown a detrimental effect on the calibration 
performance (e.g., standard error of prediction) for the prediction of meat quality parameters compared to those developed using meat cuts or homogenised samples [4].

One of the main reasons for the low performance in the NIR measurements in living animals is related with the amount of incident light (e.g., reflectance). Using this methodology, light is highly scattered by the complex structure of the skin and its main layers (epidermis (blood-free layer), dermis (vascularised layer with dense irregular connective tissue with collagenous fibers), and hypodermis (subcutaneous adipose tissue layer composed of two sublayers separated by thin connective tissue)) $[4,17,18]$. In several in vivo or live applications of NIR spectroscopy, different studies have highlighted that the light has to travel through all these layers of the skin before reaching the layer of interest (e.g., muscle), where the subcutaneous adipose tissue influencing the collected reflectance signal from the sample $[4,17,18]$. Therefore, understanding the interactions between the skin and between the different tissues and the light propagation through different layers of the tissue will be essential for the correct interpretation of results obtained using this approach in live animals $[4,18]$. Although reports can be found in the literature on the use of NIR spectroscopy to measure different properties of meat or fat composition in pigs through the skin, no information is available on the use of this technique to measure beef meat composition in live animals or on the evaluation of meat quality through the skin [3-5].

This study evaluated the potential use of NIR spectroscopy to analyze muscle and fat characteristics in beef cattle through the skin. The optical properties of tissues analyzed through the skin and the application of pattern recognition methods were used in order to demonstrate the ability of this method to analyze different tissues through the skin.

\section{Materials and Methods}

2.1. Samples. In order to study the optical properties or spectra of different tissues, two commercial meat cuts, namely, rump (Gluteous medius) and steak (Semitendinosus and Semimembranosus), were analyzed with and without the presence of the skin. Five combinations of tissue and the skin were analyzed as follows: fat, muscle, and the skin alone and either muscle or fat plus skin. A total of 90 samples were created by combining the skin, meat, and fat tissues and the two commercial meat cuts.

2.2. Near Infrared Reflectance Spectroscopy. The diffuse reflectance spectra of the samples were recorded from the flat surface using the purpose built contact probe attached by a fibre optic ( $10 \mathrm{~mm}$ diameter) cable to a Fourier transform (FT) NIR instrument (Antaris II, Thermo, USA). The instrument records spectra with resolution of $1 \mathrm{~nm}$ for the wavelength region $14,000-4000 \mathrm{~cm}^{-1}(700-2500 \mathrm{~nm})$. Data collection and processing was achieved using the Thermo interface software enabling automation of data collection provided by the Antaris II instrument. The instrument was set to average 10 readings internally for each spectrum saved. A ceramic tile or reference panel provided by the instrument manufacturer was used as a white reference between each measurement.

2.3. Chemometric Analysis. Spectra were exported from the Thermo software in GRAMS format $\left({ }^{*} . \mathrm{spc}\right)$ into The Unscrambler software (version X CAMO ASA, Oslo, Norway) for chemometric analysis. Principal component analysis (PCA) was performed with full cross validation (leave one out). The optimum numbers of terms in the PCA models were indicated by the lowest number of factors that gave the minimum value of the prediction residual error sum of squares (PRESS) in cross validation in order to avoid over fitting in the models. Preprocessing was achieved using second derivative (Savitzky-Golay derivative, 20 data points smoothing and second polynomial order) $[19,20]$.

Discrimination models were developed using partial least squares discriminant analysis regression (PLS-DA). The PLS-DA regression technique is a variant of PLS regression, where for each class, a model $(C=T . q)$, where $T$ is the PLS scores obtained from the original data using the PLS algorithm, $q$ is the vector, and $C$ is the class membership function $[21,22]$. In this study, PCA and PLS-DA models were developed using full cross validation (leave one out) and defined by the PRESS (prediction residual error sum of squares) function in order to avoid overfitting of the models (The Unscrambler, CAMO AS, version 10.3, Oslo, Norway).

\section{Results and Discussion}

Figure 1 shows the second derivative of the NIR mean spectrum of fat, muscle, fat plus skin, muscle plus skin, and skin. In the short NIR wavelength region, differences were observed around $10,750 \mathrm{~cm}^{-1}$ and $10,288 \mathrm{~cm}^{-1}$, associated with water $\left(\mathrm{O}-\mathrm{H}\right.$ bonds) $[23,24]$. Around $11,900 \mathrm{~cm}^{-1}$, $11,655 \mathrm{~cm}^{-1}, 10,929 \mathrm{~cm}^{-1}$, and $9911 \mathrm{~cm}^{-1}$ wavenumbers, values can be related with differences in water (O-H bonds) content, as well associated with $\mathrm{C}-\mathrm{H}_{2}$ third overtones $[23,24]$. Absorption bands between 10,929 and $10,800 \mathrm{~cm}^{-1}$ can be associated with lipid content of the tissue analyzed where additional bands associated with the $\mathrm{CH}$ stretch overtones were observed between 11,655 and $10,929 \mathrm{~cm}^{-1}$ $[23,24]$. Absorption bands between 10,400 and $9911 \mathrm{~cm}^{-1}$ are mainly associated with water (O-H bonds) $[23,24]$.

The most relevant changes were observed in the long NIR wavelength region where differences were observed at $7100 \mathrm{~cm}^{-1}$ (O-H and C-H), $5263 \mathrm{~cm}^{-1}(\mathrm{O}-\mathrm{H}$, mainly related with water/moisture), and between $4762-4350 \mathrm{~cm}^{-1}(\mathrm{CH}$ combination tones). The same wavenumber range (4762$4350 \mathrm{~cm}^{-1}$ ) was reported by other authors to be associated with cartilage when pure bovine cartilage samples were analyzed using NIR spectroscopy [25-27]. These wavenumbers were associated with $\mathrm{C}-\mathrm{H}$ combination and asymmetric first overtones of C-N-C stretch and $\mathrm{N}-\mathrm{H}$ of proteins [25-27]. This region appears to be unique between the different tissues (e.g., fat, muscle, and skin) analyzed, indicating that differences in the absorbance values can be attributed to different protein and collagen ratios between tissues. In the same region, shifts were also observed around $4329 \mathrm{~cm}^{-1}$ (e.g., lipids, collagen, and proteoglycans) and between $4762-$ 


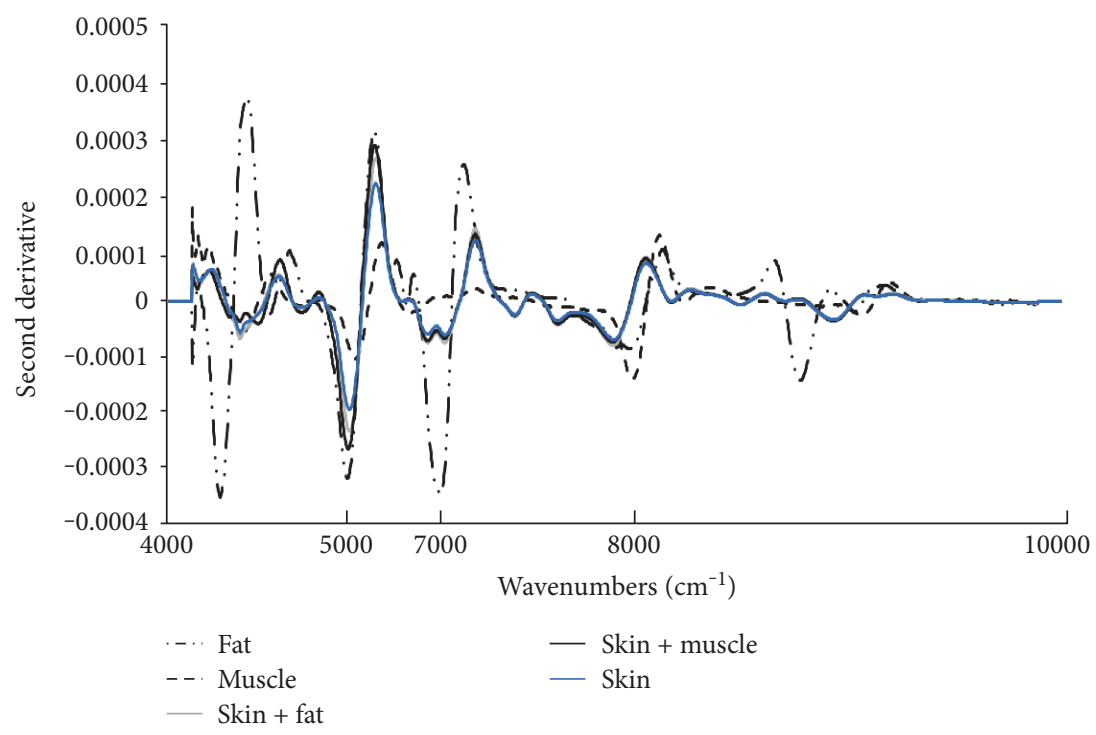

FIGURE 1: Second derivative of the average of the near infrared mean spectrum of skin, muscle, fat, skin plus fat, and skin plus muscle.

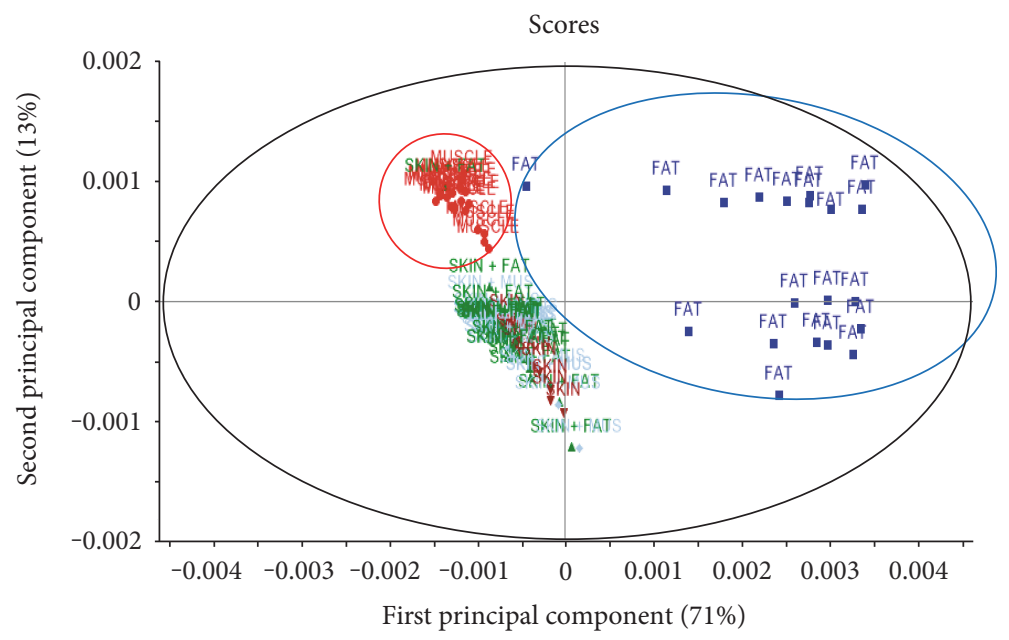

FIGURE 2: Score plot of fat, muscle, skin, skin plus fat, and skin plus muscle samples analyzed using near infrared spectroscopy.

$4350 \mathrm{~cm}^{-1}(\mathrm{~N}-\mathrm{H}$ and $\mathrm{O}-\mathrm{H})[6,17,23-27]$. Overall, the visual inspection of the wavenumber region between 5263 and $4175 \mathrm{~cm}^{-1}$ indicated that long wavelengths in the NIR region can be useful to identify differences between tissues. However, the use of NIR spectroscopy to analyze in vivo samples or live animals might be limited to the NIR spectral range between 5200 and $4370 \mathrm{~cm}^{-1}$ due to the large effect of water $\left(5263 \mathrm{~cm}^{-1}\right)$. Other authors reported similar results when different animal tissues were analyzed using NIR spectroscopy $[6,17,27,28]$.

In order to further test and evaluate the interactions between different tissues (skin, muscle, and fat) the NIR spectra were analyzed using PCA (see Figure 2). Separation between "fat samples" and the other samples (skin and skin + muscle) was observed along PC1, while separation between muscles was achieved in PC2. The amount of variation explained for each PC was $71 \%$ and $13 \%$ for PC1 and
PC2, respectively. Examination of the PCA loadings is very important as they might indicate specific wavelengths or regions in the NIR range related with the variability observed in the PCA score plot. Figure 3 shows the PCA loadings of the first two principal components (PCs) associated with the PCA shown in Figure 2. Wavenumbers associated with lipids and moisture content were the most relevant in explaining the separation between samples [23, 24]. Clear differences between the loadings in PC1 and PC2 were observed, indicating that different spectral information might be associated with the different tissues or combination of samples analyzed (see Figures 4 and 5).

The PLS-DA models were used to further evaluate the ability of NIR spectroscopy to identify different tissue types analyzed through the skin (see Figure 6). Even though the classification results obtained were between 60 and $70 \%$ (correct classification), the overall results indicated that the 


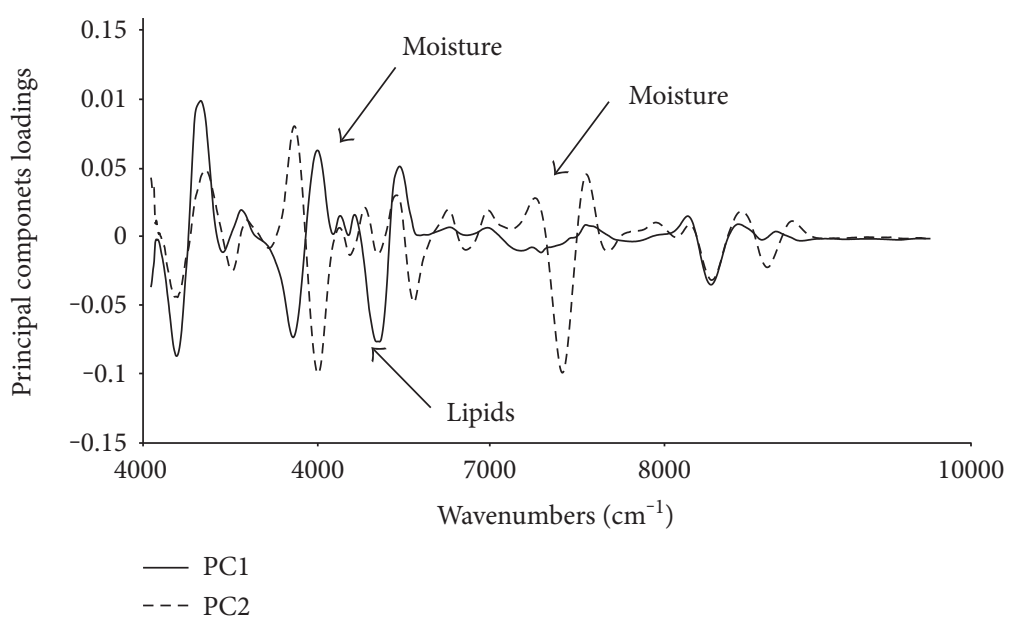

FIGURE 3: Loadings derived from the PCA used to analyze fat, muscle, skin, skin plus fat, and skin plus muscle samples analyzed using near infrared spectroscopy.

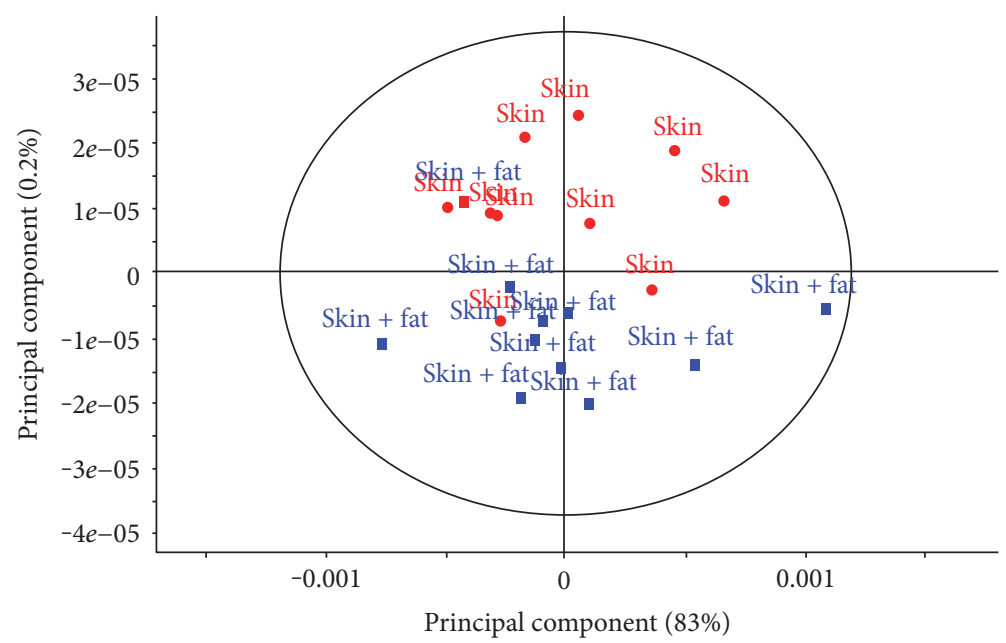

FIGURE 4: Score plot of fat and skin plus fat in the meat samples analyzed using near infrared spectroscopy.

NIR method evaluated in this study is capable to identify different tissues through the skin.

Zamora-Rojas et al. [4] showed that information related with the optical properties of pigskin (epidermis and dermis) might be limited to the short NIR wavelength range (below $6250 \mathrm{~cm}^{-1}$ ) [29]. However, other studies indicated that the optical properties of dermis tissues from pigs can be observed in the $10,929-6850 \mathrm{~cm}^{-1}$ NIR range, while studies of epidermis and dermis using wavenumbers between 10,000 and $6200 \mathrm{~cm}^{-1}$ were reported by other authors using the same animal species [30-32]. Other characteristics of the skin such as the presence of the skin can also contribute to the optical properties of the system. Hair structure, type, and pigmentation are important factors that determine the coloration of a species, which influences the spectral reflectance and absorption for any given species [13, 15]. Most terrestrial mammals have two hair types, namely, guard hairs and underfur $[13,15]$. Guard hairs are typically longer and thicker and have a complex physical structure. Underfur is short, fine, and dense, with a simple physical structure and little variability in coloration $[13,15]$.

It is well known that light penetration depth in a specific sample is a function of the geometry of the optical probe, the scattering and the absorption characteristics of the sample $[33,34]$. Typical penetration depth within biological tissues is at least $10 \mathrm{~mm}$ or longer depending upon the tissue studied [34]. When light enters the tissues, it is either absorbed or scattered, based on wavelength and differences in chemical composition of the tissue $[33,34]$. Since different types of molecules vibrate at different frequencies, different compounds in the tissue can be identified based on the frequencies of light that are detected by the instrument. For example, in the $13,900-9386 \mathrm{~cm}^{-1}$ wavenumber range, second and third overtones of the $\mathrm{OH}, \mathrm{CH}$, and $\mathrm{NH}$ vibrational transitions are detected in addition to the combination bands from other types of vibration $[23,33]$. The peak at 


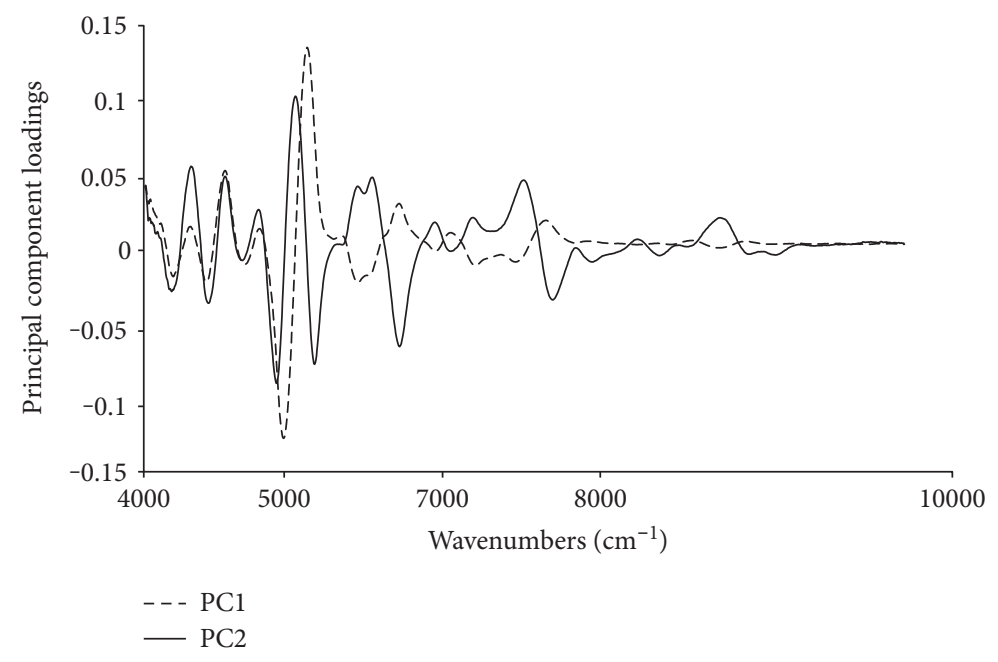

FIGURE 5: Loadings derived from the PCA used to analyze fat and skin plus fat in the meat samples analyzed using near infrared spectroscopy.

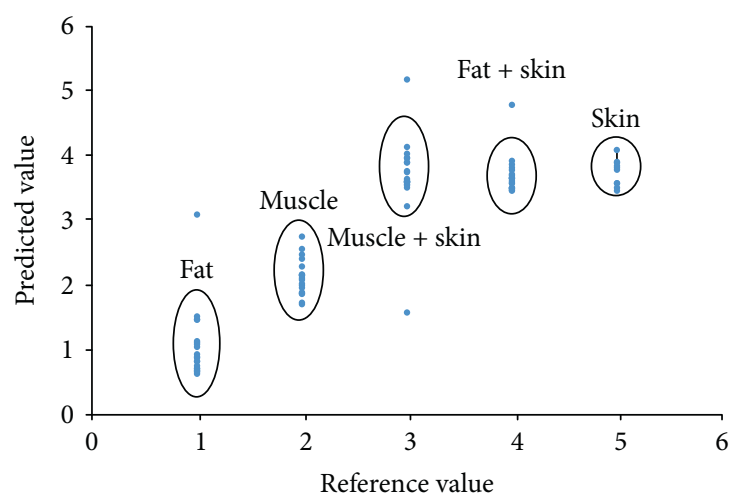

(a) All samples

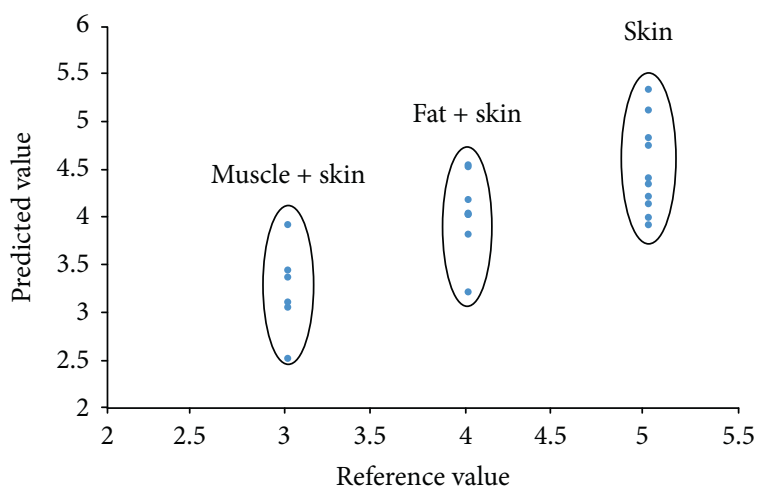

(b) Steak

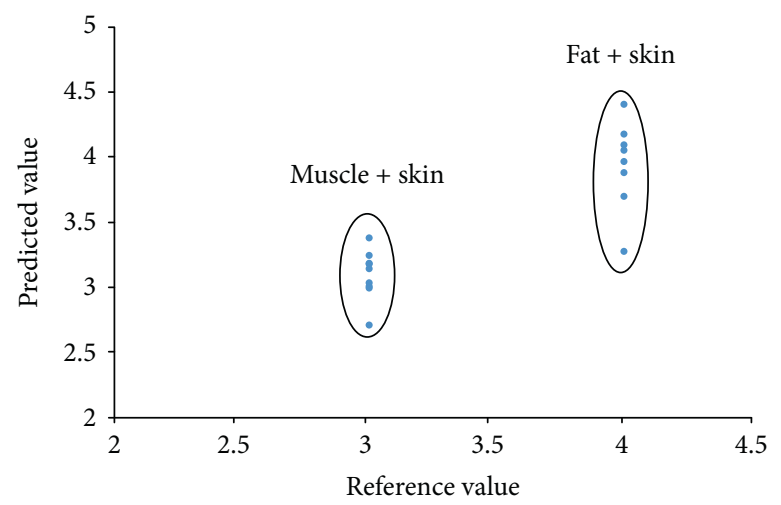

(c) Rump

FIGURE 6: Partial least squares discriminant analysis of different types of beef tissues analyzed using near infrared reflectance spectroscopy.

$10,750 \mathrm{~cm}^{-1}$, which predominates on the fat spectrum, corresponds to that reported for fat, while peaks in the 10,400 to $9911 \mathrm{~cm}^{-1}$, region for the other tissues corresponds to that reported for water $[33,35]$. These authors indicated that by dissecting and reconstructing the tissue layers of varying thickness, a change in composition could be detected by NIR spectroscopy to a depth of approximately $1 \mathrm{~cm}$. For the estimation of body composition in pigs, the spectrum for the tissue composite appears to be influenced predominately by the composition of the skin layer and to a lesser extent by the presence of the fat and muscle layers $[33,36]$.

\section{Conclusions}

The results from this study demonstrated that the NIR region has the potential to monitor some beef meat properties 
associated with fat or muscle noninvasively through the skin. The proposed method would provide beef producers or industry with a powerful tool to monitor more closely the effects of health, nutrition, or product characteristics with the goal of producing a consistently uniform product and maximize profits assuring consumer with a product of high quality. Although these results look promising, more experiments and research need to be carried out before recommending the beef industry to use this technology in live animals.

\section{Conflicts of Interest}

The authors declare that there is no conflict of interest regarding the publication of this paper.

\section{References}

[1] D. Alomar, C. Gallo, M. Castaneda, and R. Fuchslocher, "Chemical and discriminant analysis of bovine meat by near infrared reflectance spectroscopy (NIRS)," Meat Science, vol. 63, pp. 441-450, 2003.

[2] N. Prieto, R. Roehe, P. Lavín, G. Batten, and S. Andrés, “Application of near infrared reflectance spectroscopy to predict meat and meat products quality: a review," Meat Science, vol. 83, pp. 175-186, 2009.

[3] D. Pérez-Marín, E. De Pedro, J. E. Guerrero-Ginel, and A. Garrido-Varo, "A feasibility study on the use of near-infrared spectroscopy for prediction of the fatty acid profile in live Iberian pigs and carcasses," Meat Science, vol. 83, pp. 627-633, 2009.

[4] E. Zamora-Rojas, B. Aernouts, A. Garrido-Varo, D. Pérez-Marín, J. E. Guerrero-Ginel, and W. Saeys, "Double integrating spheres measurements for estimating optical properties of pig subcutaneous adipose tissue," Innovative Food Science and Emerging Technologies, vol. 19, pp. 218-226, 2013.

[5] E. Zamora-Rojas, A. Garrido-Varo, E. De Pedro-Sanz, J. E. Guerrero-Ginel, and D. Pérez-Marín, "Prediction of fatty acid content in pig adipose tissue by near infrared spectroscopy: at-line versus in-situ analysis," Meat Science, vol. 95, no. 3, pp. 503-511, 2013.

[6] H. Azizian, J. K. G. Kramer, S. B. Heymsfield, and S. Winsborough, "Fourier transform near infrared spectroscopy: a newly developed, non-invasive method to measure body fat non-invasive body fat content measurement using FT-NIR," Lipids, vol. 43, pp. 97-103, 2008.

[7] A. N. Bashkatov, E. A. Genina, V. I. Kochubey, and V. V. Tuchin, "Optical properties of human skin, subcutaneous and mucous tissues in the wavelength range from 400 to 2000 nm," Journal of Physics D: Applied Physics, vol. 38, pp. 2543-2555, 2005.

[8] A. N. Bashkatov, E. A. Genina, V. I. Kochubey, and V. V. Tuchin, "Optical properties of the subcutaneous adipose tissue in the spectral range 400-2500 nm," Optics and Spectroscopy, vol. 99, no. 5, pp. 836-842, 2005.

[9] S. L. Jacques, "Optical properties of biological tissues: a review," Physics in Medicine and Biology, vol. 58, pp. R37R61, 2013.

[10] E. Dufour, Principles of Infrared Spectroscopy, Academic Press, Elsevier Science \& Technology Books, San Diego, CA, USA, 2008.
[11] B. G. Osborne, T. Fearn, and T. Davies, "Practical NIR spectroscopy with applications in food and beverage analysis," in Food and Beverage Analysis, B. G. Osborne, T. Fearn and P. T. Hindle, Eds., pp. 11-35, Longmand, Essex, 1993.

[12] J. Workman, "A review of process near infrared spectroscopy: 1980-1994," Journal of Near Infrared Spectroscopy, vol. 1, no. 4, p. 16, 1993.

[13] C. D. Hutchinson, T. E. Allen, and F. B. Spence, "Measurement of the reflectance for solar radiation of the coats of live animals," Comparative Biochemistry and Physiology, vol. 52A, pp. 343-349, 1975.

[14] J. Pringle, C. Roberts, M. Kohl, and P. Lekeux, "Near infrared spectroscopy in large animals: optical path length and influence of hair covering and epidermal pigmentation," The Veterinary Journal, vol. 158, pp. 48-52, 1999.

[15] P. Terletzky, R. D. Ramsey, and C. M. U. Neale, "Spectral characteristics of domestic and wild mammals," GIScience and Remote Sensing, vol. 49, pp. 597-608, 2012.

[16] M. Prevolnik, M. Candek-Potokar, and D. Skorjank, “Ability of NIR spectroscopy to predict chemical composition and quality - a review," Czech Journal of Animal Science, vol. 49, pp. 500-510, 2004.

[17] H. Ding, J. Q. Lu, K. M. Jacobs, and X. Hu, "Determination of refractive indices of porcine skin tissues and intra lipid at eight wavelengths between 325 and $1557 \mathrm{~nm}$," Journal of the Optical Society of America, vol. 22, no. 6, pp. 1151-1157, 2005.

[18] D. Renaudeau, M. Leclercq-Smekens, and M. Herin, "Differences in skin characteristics in European (large white) and Carribbean (Creole) growing pigs with reference to thermoregulation," Animal Research, vol. 55, pp. 207-219, 2006.

[19] W. Hruschka, Data Analysis: Wavelength Selection Methods, American Association of Analytical Chemists, 2nd edition, 2001.

[20] A. Savitzky and M. J. E. Golay, "Smoothing and differentiation of data by simplified least squares procedures," Analytical Chemistry, vol. 36, pp. 1627-1632, 1964.

[21] R. G. Brereton, Applied Chemometrics for Scientist, Wiley, 2008.

[22] R. G. Brereton, "Introduction to multivariate calibration in analytical chemistry," The Analyst, vol. 125, pp. 2125-2154, 2000.

[23] L. G. Weyer, "Near-infrared spectroscopy of organic substances," Applied Spectroscopy Reviews, vol. 21, pp. 1-43, 1985.

[24] J. Workman and L. Weyer, Practical Guide to Interpretive near-Infrared Spectroscopy, CRC Press Taylor and Francis Group, Boca Raton, 2008.

[25] C. P. Brown, C. Jayadev, S. Glyn-Jones et al., "Characterization of early stage cartilage degradation using diffuse reflectance near infrared spectroscopy," Physics in Medicine and Biology, vol. 56, pp. 2299-2307, 2011.

[26] C. P. Brown, A. Oloyede, R. W. Crawford, G. E. Thomas, A. J. Price, and H. S. Gill, "Acoustic, mechanical and near-infrared profiling of osteoarthritic progression in bovine joints," Physics in Medicine and Biology, vol. 57, pp. 547-559, 2012.

[27] U. P. Palukuru, C. M. McGoverin, and N. Pleshko, “Assessment of hyaline cartilage matrix composition using near infrared spectroscopy," Matrix Biology, vol. 38, pp. 3-11, 2014.

[28] M. V. Padalkar, R. G. Spencer, and N. Pleshko, "Near infrared spectroscopic evaluation of water in hyaline cartilage," Annals of Biomedical Engineering, vol. 41, no. 11, pp. 2426-2436, 2013. 
[29] A. N. Bashkatov, E. A. Genina, and V. V. Tuchin, "Optical properties of skin, subcutaneous and muscle tissues: a review," Journal of Innovative Optical Health Sciences, vol. 4, no. 1, pp. 9-38, 2011.

[30] A. Cain, T. Milner, S. Telenkov, K. Schuster, K. Stockton, and D. Stolarski, "Porcine skin thermal response to near-IR lasers using a fast infrared camera," in Laser Interaction with Tissue and Cells, S. L. Jacques and P. W. Roach, Eds., pp. 313-324, SPIE, Bellingham, WA, 2004.

[31] Y. Du, X. H. Hu, M. Cariveau, X. Ma, G. W. Kalmus, and J. Q. $\mathrm{Lu}$, "Optical properties of porcine skin dermis between $900 \mathrm{~nm}$ and $1500 \mathrm{~nm}$," Physics in Medicine and Biology, vol. 46, pp. 167-181, 2001.

[32] X. Ma, J. Q. Lu, H. Ding, and X. H. Hu, "Bulk optical parameters of porcine skin dermis at eight wavelengths from 325 to 1557 nm," Optics Letters, vol. 30, no. 4, pp. 412-414, 2005.

[33] F. Martelli, "An ABC of near infrared photon migration in tissues: the diffuse regime of propagation," Journal of Near Infrared Spectroscopy, vol. 20, pp. 29-42, 2012.

[34] I. Murray and I. Cowe, "Sample preparation in near infrared spectroscopy in agriculture," American Society of Agronomy, Crop Science Society of America, Soil Science Society of America, Madison, WI, USA, 2004.

[35] J. M. Conway, K. H. Norris, and C. E. Bodwell, “A new approach for the estimation of body composition: infrared interactance," The American Journal of Clinical Nutrition, vol. 40, pp. 1123-1130, 1984.

[36] A. D. Mitchell, A. M. Scholz, and M. B. Solomon, "Estimation of body composition of pigs by a near infrared interactance probe technique," Archiv Tierzucht Dummerstorf, vol. 48, pp. 580-591, 2005. 

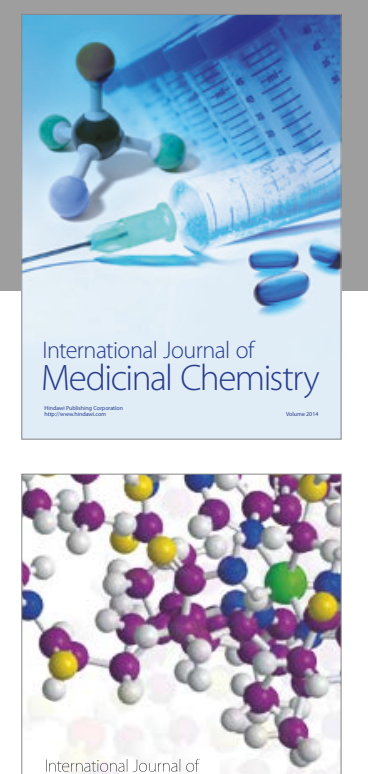

Carbohydrate Chemistry

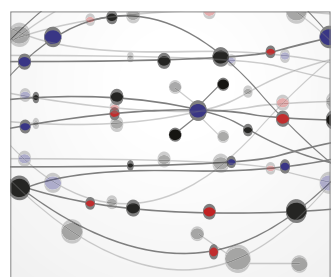

The Scientific World Journal
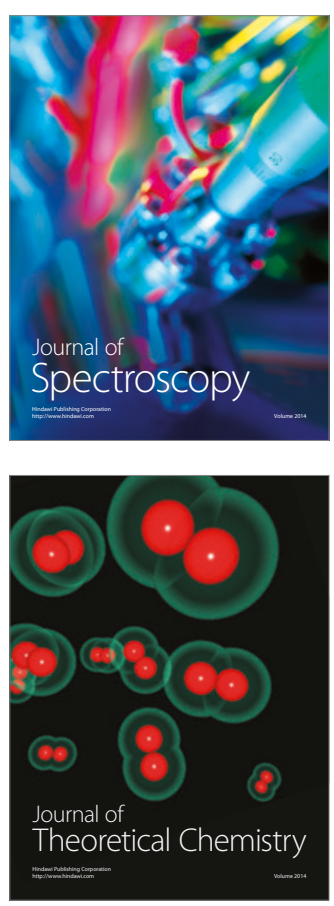
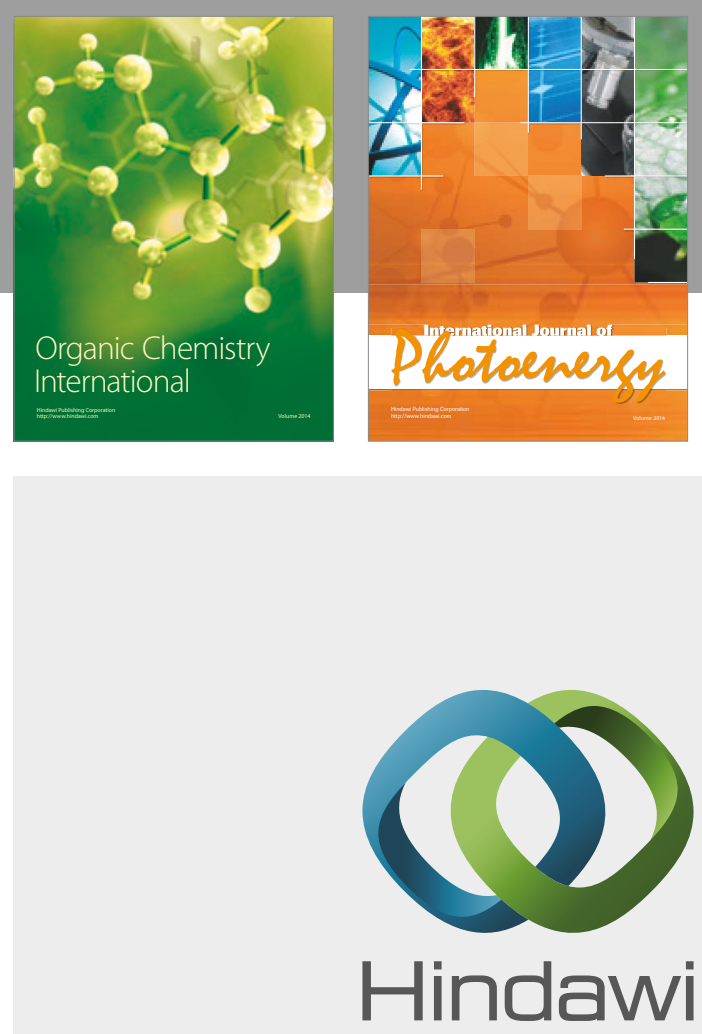

Submit your manuscripts at

https://www.hindawi.com

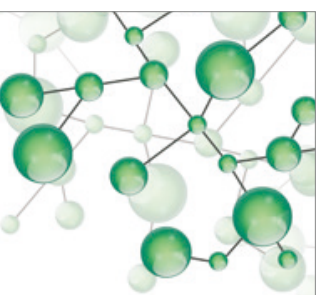

International Journal of

Inorganic Chemistry

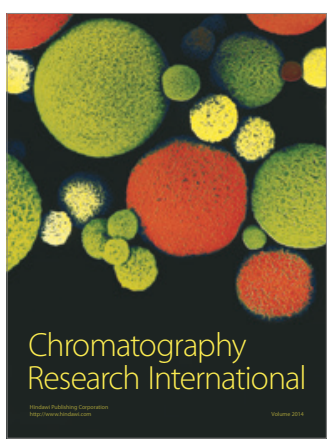

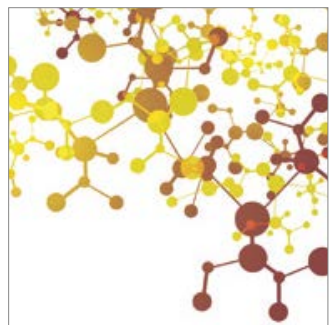

Applied Chemistry
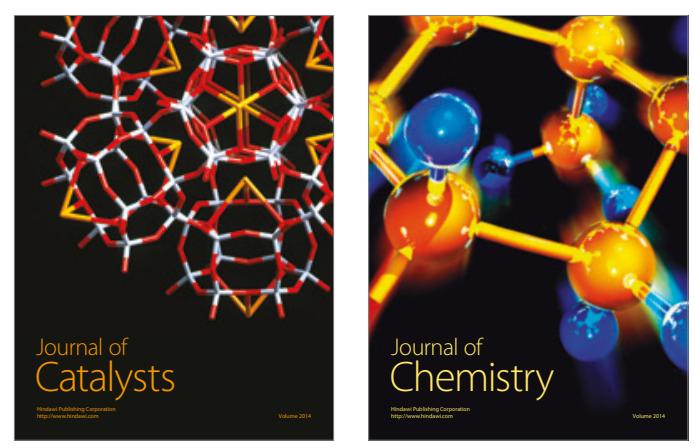
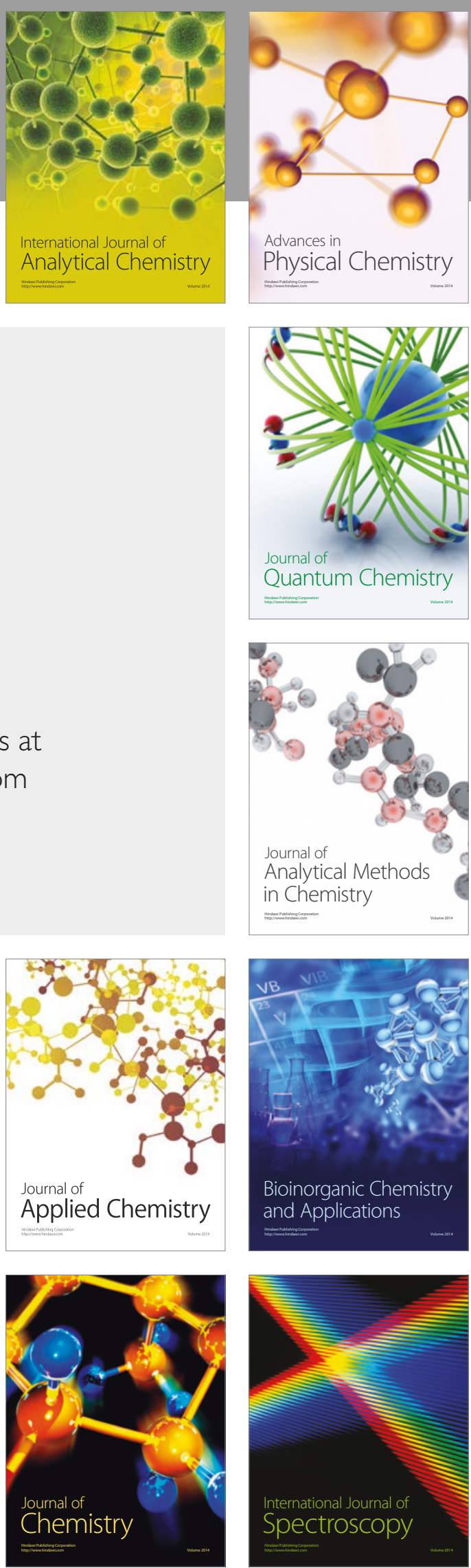